\title{
Crescimento de mudas de Chamaecyparis lawsoniana em diferentes níveis de adubação mineral do substrato e em cobertura
}

\section{Growth of Chamaecyparis lawsoniana nursery trees with different levels of covering and substrate mineral fertilization}

\author{
Andressa Emanoela do Prado ${ }^{1}$; Gabriely Pinto Pereira ${ }^{1}$; \\ Denise Bruginski de Carvalho²; Ruy Inacio Neiva de Carvalho ${ }^{3 *}$
}

\begin{abstract}
Resumo
Foram realizados dois experimentos simultâneos no Viveiro de Plantas Ornamentais da Universidade Federal do Paraná com o objetivo de avaliar o efeito da adubação mineral sobre o crescimento de mudas de Chamaecyparis lawsoniana plantadas diretamente no campo e em recipientes individuais. Utilizouse o delineamento completamente casualizado com cinco combinações de NPK (4-30-10) mais uréia, em gramas, $(0+0 ; 30+10 ; 60+20 ; 90+30$ e $120+40$, respectivamente para o campo e $0+0 ; 10+$ $4 ; 20+8 ; 30+12$ e $40+16$, respectivamente para os recipientes) e quatro repetições. O crescimento das plantas foi observado durante um ano, realizando-se avaliações de altura da muda e diâmetro do tronco a cada dois meses. A adubação em cobertura a campo não estimulou o crescimento das mudas. A adubação de substrato promoveu maior crescimento de mudas em recipiente em altura e em diâmetro de tronco mais significativamente no período de setembro a maio. $\mathrm{O}$ crescimento em diâmetro do tronco da muda foi mais influenciado, demonstrando que o crescimento secundário da planta foi mais estimulado pela adubação. $\mathrm{O}$ crescimento das mudas a campo foi maior que o ocorrido em recipientes.

Palavras-chave: Coníferas, plantas ornamentais, nutrição, fisiologia vegetal
\end{abstract}

\begin{abstract}
Two simultaneous experiments were accomplished in the Nursery of Ornamental Plants of the Federal University of Paraná State with the objective of evaluating the effect of mineral fertilization on the growth of nursery trees of Chamaecyparis lawsoniana planted directly in the field and in individual packings. The experimental design was the completely randomized with five combinations of NPK $4-30-10+$ urea, in grams $(0+0 ; 30+10 ; 60+20 ; 90+30$ and $120+40$ for the field and $0+0 ; 10+$ $4 ; 20+8 ; 30+12$ and $40+16$ for the packings) and four replications. The growth of the plants was observed during one year and the height of plants and the diameter of the trunks were evaluated each two months. The fertilization in covering in the field did not stimulate the growth of the plants. The substrate fertilization promoted significantly higher growth of plants in height and diameter of trunks in the period from September to May. The trunk diameter was more influenced, demonstrating that the secondary growth of the plant is more stimulated by the fertilization. The plant growth in the field was greater than the plant growth in individual packings.
\end{abstract}

Key words: Conifers, ornamental plants, nutrition, vegetal physiology

\footnotetext{
Estudante de Agronomia, Pontifícia Universidade Católica do Paraná, CCAA. E-mail: andressae.prado@hotmail.com; gabyp. pereira@hotmail.com

2 Docente do Curso de Especialização em Gestão dos Recursos Naturais do Centro de Ciências Agrárias e Ambientais da Pontifícia Universidade Católica do Paraná, São José dos Pinhais, PR. E-mail: denise.bcarvalho@terra.com.br.

3 Eng. Agrônomo, Dr., Bolsista de Produtividade em Pesquisa do CNPq, Professor Titular do Centro de Ciências Agrárias e Ambientais da Pontifícia Universidade Católica do Paraná, Campus São José dos Pinhais. E-mail: ruy.carvalho@pucpr.br Autor para correspondência
} 


\section{Introdução}

As diversas espécies de coníferas cultivadas no Brasil são na maioria exóticas. A espécie Chamaecyparis lawsoniana possui mais de 200 variedades de acordo com a cor da folhagem, forma da copa e altura da planta, e pode atingir de 40 a $50 \mathrm{~m}$ de altura, embora as podas da copa alterem sua forma típica (LORENZI; SOUZA, 1995). Pertence à família Cupressaceae e ordem Coniferae das Gimnospermas. Na região metropolitana de Curitiba, a variedade 'Aurea' é cultivada em viveiros e utilizada em jardins e praças.

A espécie é endêmica da região norte dos EUA (BRILES et al., 2008) e tem grande procura como conífera ornamental para plantio em parques, jardins públicos e residenciais nas cidades do Sul do Brasil, onde é conhecida como falso-cipreste ou tuia-maçã. Adapta-se muito bem ao clima da região, principalmente com relação à resistência ao frio e tolerância a lugares úmidos (STUMPF; GROLLI; SILVA, 2001). Além do uso ornamental, tem se estudado o efeito antibiótico de compostos bioativos presentes em seu óleo essencial, como os diterpenos ferruginol e pisiferol (SMITH et al., 2007). Algumas substâncias contidas no óleo podem causar efeitos tóxicos na pele de animais, entretanto, baixas concentrações não apresentam toxidez (CRAIG et al., 2004).

Emboraalgumas coníferas possam serpropagadas através de sementes, certas características desejáveis somente podem ser mantidas por propagação vegetativa, especialmente a estaquia, que é o método mais utilizado para a propagação desta espécie (STUMPF; GROLLI; SILVA, 1999; STUMPF; GROLLI; SCZEPANSKI, 2001). Os produtores de coníferas produzem suas mudas por estaquia e, em seguida, as transplantam para recipientes individuais ou diretamente no campo, onde as mudas permanecem até atingir a altura considerada ótima para venda, em torno de $80 \mathrm{~cm}$ de altura. Este padrão só é atingido, muitas vezes, após mais de dois anos em virtude do lento crescimento inicial destas plantas. Evidencia-se, então, a necessidade de estudos a respeito dessa fase de cultivo em viveiro para acelerar seu crescimento e minimizar os custos de produção. Há falta de conhecimento a respeito da exigência nutricional da espécie e a adubação é feita com base em informações genéricas de outras plantas e, assim, pode-se estar desperdiçando nutrientes ou mesmo retardando o crescimento da planta.

Dentre os nutrientes requeridos para o crescimento e desenvolvimento das plantas destacam-se o nitrogênio, que está relacionado com a fotossíntese, respiração, atividade das raízes e absorção iônica de outros nutrientes; o fósforo, como fonte de energia e formação de compostos essenciais em processos metabólicos; e o potássio, que participa do transporte e armazenamento de assimilados, e como ativador de funções enzimáticas (RAIJ, 1991). Quando estes nutrientes não estão devidamente disponíveis para a absorção há a necessidade de se realizar a adubação.

A C. lawsoniana poderia ser utilizada como uma nova alternativa em programas de reflorestamento para seqüestro de carbono devido ao acúmulo de matéria seca no caule, onde a maior parte do carbono assimilado é armazenado. Atualmente, existe um consenso mundial de que estratégias devem ser estudadas e empregadas para redução da concentração do $\mathrm{CO}_{2}$ atmosférico, na tentativa de reduzir o risco de eventuais catástrofes mundiais. Entre as estratégias para redução da concentração de gás carbônico na atmosfera, destaca-se o seqüestro do carbono através do plantio e manejo de florestas (SOARES; OLIVEIRA, 2002).

Este trabalho foi realizado com o objetivo de avaliar o efeito da adubação mineral do substrato e em cobertura sobre o crescimento de mudas de Chamaecyparis lawsoniana. 


\section{Material e métodos}

Foram realizados dois experimentos simultâneos conduzidos no Viveiro de Plantas Ornamentais da Universidade Federal do Paraná localizado no Município de Pinhais, Região Metropolitana de Curitiba, para avaliação do efeito da adubação sobre mudas cultivadas em recipientes individuais e plantadas diretamente no campo.

Em ambos os experimentos, as mudas de $C$. lawsoniana foram obtidas por estaquia herbácea de ramos no próprio viveiro e transplantadas para o campo e para os recipientes. Foram estudados dois fatores referentes ao efeito da adubação mineral e ao tempo de crescimento das plantas.

No experimento a campo, o espaçamento de plantio foi de $1,0 \times 1,0 \mathrm{~m}$. A calagem foi realizada na dose de $300 \mathrm{~g}$ de calcário por cova 30 dias antes do plantio das mudas. As características químicas do solo da área estão na Tabela 1. A adubação foi realizada em cobertura, em duas parcelas, no primeiro e terceiro mês após o transplante em um círculo a 30 $\mathrm{cm}$ ao redor da planta, seguida de incorporação com enxada. As plantas foram irrigadas com mangueira após a adubação.

Tabela 1. Laudo de análise química do substrato para recipientes e do solo. Curitiba, UFPR.

\begin{tabular}{|c|c|c|c|c|c|c|c|c|c|c|}
\hline \multirow{2}{*}{$\begin{array}{l}\mathbf{p H} \\
\mathrm{CaCl}_{2}\end{array}$} & $\mathbf{A l}^{+3}$ & $\mathbf{H}+\mathbf{A l}$ & $\mathrm{Ca}^{+2}+\mathrm{Mg}^{+2}$ & $\mathbf{C a}^{+2}$ & $\mathbf{K}^{+}$ & $T$ & $\mathbf{P}$ & C & M & V \\
\hline & \multicolumn{6}{|c|}{--------------------- $\mathrm{cmol}_{\mathrm{c}} \mathrm{dm}^{-3}$------------------ } & $\mathrm{mg} \mathrm{dm}{ }^{-3}$ & $\mathrm{~g} \mathrm{dm}^{-3}$ & \multicolumn{2}{|c|}{------- \% ------ } \\
\hline \multicolumn{11}{|l|}{ Solo } \\
\hline 4,6 & 1,9 & 9,7 & 5,3 & 3,9 & 0,36 & 15,4 & 24 & 44,1 & 25,1 & 36,8 \\
\hline \multicolumn{11}{|c|}{ Substrato para recipiente } \\
\hline 5,6 & 0,0 & 4,3 & 16,4 & 8,7 & 2,80 & 23,5 & 320 & 44,1 & 0,0 & 81,7 \\
\hline
\end{tabular}

Departamento de Solos da UFPR.

Realizaram-se cinco níveis de adubação por muda combinando-se o adubo formulado NPK (4-30-10 na forma de sulfato de amônio, superfosfato simples e cloreto de potássio) mais uréia (Tabela 2).

Foram feitas avaliações após 1, 3, 5, 7, 9, 11 e 13 meses do plantio realizado em maio, medindo-se, em cada época, a altura da muda e o diâmetro do tronco a $3 \mathrm{~cm}$ do solo. As dimensões médias iniciais das mudas no plantio foram altura de $22,9 \mathrm{~cm}$ e diâmetro de $0,31 \mathrm{~cm}$.

No segundo experimento, o substrato utilizado nos recipientes foi preparado por meio de uma mistura de solo e esterco bovino. As características químicas do substrato utilizado estão apresentadas na Tabela 1.

Foram utilizados recipientes plásticos pretos de $3.384 \mathrm{~cm}^{3}$ com o substrato acrescido de $50 \mathrm{~g}$ de calcário e mantidos lado a lado em linhas espaçadas de $0,5 \mathrm{~m}$. Foram efetuados cinco níveis de adubação por recipiente combinando-se o adubo formulado NPK (4-30-10) e a uréia (Tabela 2). Foram feitas uma avaliação inicial no plantio, em julho, e seis avaliações bimestrais medindo-se, em cada época, a altura da muda e o diâmetro do tronco a $3 \mathrm{~cm}$ do substrato. 
Tabela 2. Adubações realizadas a campo e em recipientes para crescimento de mudas de Chamaecyparis lawsoniana em Pinhais, Paraná.

\begin{tabular}{|c|c|c|c|c|c|}
\hline \multirow{2}{*}{$\begin{array}{c}\text { Tratamento } \\
\text { NPK (4-30-10) } \\
+ \text { Uréia } \\
\left.\text { (g planta }^{-1}\right)\end{array}$} & \multicolumn{3}{|c|}{$\mathbf{N}\left(\right.$ g planta $\left.^{-1}\right)$} & \multirow{2}{*}{$\begin{array}{c}\mathbf{P}_{2} \mathbf{O}_{5}\left(\mathbf{g ~ p l a n t a}^{-1}\right) \\
\text { (Superfosfato } \\
\text { simples) }\end{array}$} & \multirow{2}{*}{$\begin{array}{c}\mathbf{K}_{2} \mathbf{O}\left(\mathbf{g ~ p l a n t a}^{-1}\right) \\
\text { (Cloreto de } \\
\text { potássio })\end{array}$} \\
\hline & $\begin{array}{l}\text { Sulfato de } \\
\text { amônio }\end{array}$ & Uréia & Total & & \\
\hline \multicolumn{6}{|c|}{ Adubação no solo a campo } \\
\hline $0+0$ & 0 & 0 & 0 & 0 & 0 \\
\hline $30+10$ & 1,2 & 4,5 & 5,7 & 9,0 & 3,0 \\
\hline $60+20$ & 2,4 & 9,0 & 11,4 & 18,0 & 6,0 \\
\hline $90+30$ & 3,6 & 13,5 & 17,1 & 27,0 & 9,0 \\
\hline $120+40$ & 4,8 & 18,0 & 22,8 & 36,0 & 12,0 \\
\hline \multicolumn{6}{|c|}{ Adubação do substrato em recipiente } \\
\hline $0+0$ & 0 & 0 & 0 & 0 & 0 \\
\hline $10+4$ & 0,4 & 1,8 & 2,2 & 3,0 & 1,0 \\
\hline $20+8$ & 0,8 & 3,6 & 4,4 & 6,0 & 2,0 \\
\hline $30+12$ & 1,2 & 5,4 & 6,6 & 9,0 & 3,0 \\
\hline $40+16$ & 1,6 & 7,2 & 8,8 & 12,0 & 4,0 \\
\hline
\end{tabular}

As estacas enraizadas foram selecionadas apresentando altura média de $18,1 \mathrm{~cm}$ e diâmetro médio do tronco a $3 \mathrm{~cm}$ do substrato de $0,24 \mathrm{~cm}$. As mudas sofreram podas de encurtamento de raízes a $10 \mathrm{~cm}$ da estaca e foram transplantadas individualmente para os recipientes com o substrato preparado e adubado com 30 dias de antecedência.

O delineamento experimental utilizado em ambos os experimentos foi o completamente casualizado num arranjo fatorial $5 \times 7$ com cinco níveis de adubação e sete épocas de avaliação, com quatro repetições. As parcelas do experimento a campo continham 16 plantas ( 4 x $4 \mathrm{~m}$ ) sendo úteis as quatro centrais e as parcelas do experimento de substrato continham 10 recipientes. Os dados foram submetidos à análise de variância e as médias com diferença significativa pelo teste $\mathrm{F}$ foram submetidas ao teste de Duncan ao nível de significância de 5\% para o fator adubação e à análise de regressão para o fator época de avaliação. Foi realizada também a análise de correlação entre as variáveis altura e diâmetro de tronco das plantas.

\section{Resultados e discussão}

A adubação em cobertura a campo não interferiu significativamente no crescimento das mudas em cada avaliação realizada (Tabelas 3 e 4). A ausência de resposta à adubação em cobertura em mudas de coníferas pode evidenciar as condições adequadas de fertilidade do solo e a baixa exigência de nutrição adicional destas plantas na fase inicial de cultivo a campo, onde não há restrição para o crescimento de raízes. O solo da área experimental apresentou níveis altos de fósforo, potássio, magnésio e carbono e nível médio de cálcio (Tabela 1) que são favoráveis ao crescimento vegetal, porém a baixa saturação por bases, o nível alto de alumínio e a média saturação por alumínio podem representar limitações à nutrição e, consequentemente, ao crescimento das plantas (TOMÉ JUNIOR, 1997). O conteúdo elevado de fósforo e potássio do solo foi suficiente para suprir as necessidades para o crescimento das plantas durante o primeiro ano. 
Tabela 3. Altura de mudas (cm) de Chamaecyparis lawsoniana a campo em função da adubação do solo em Pinhais, Paraná.

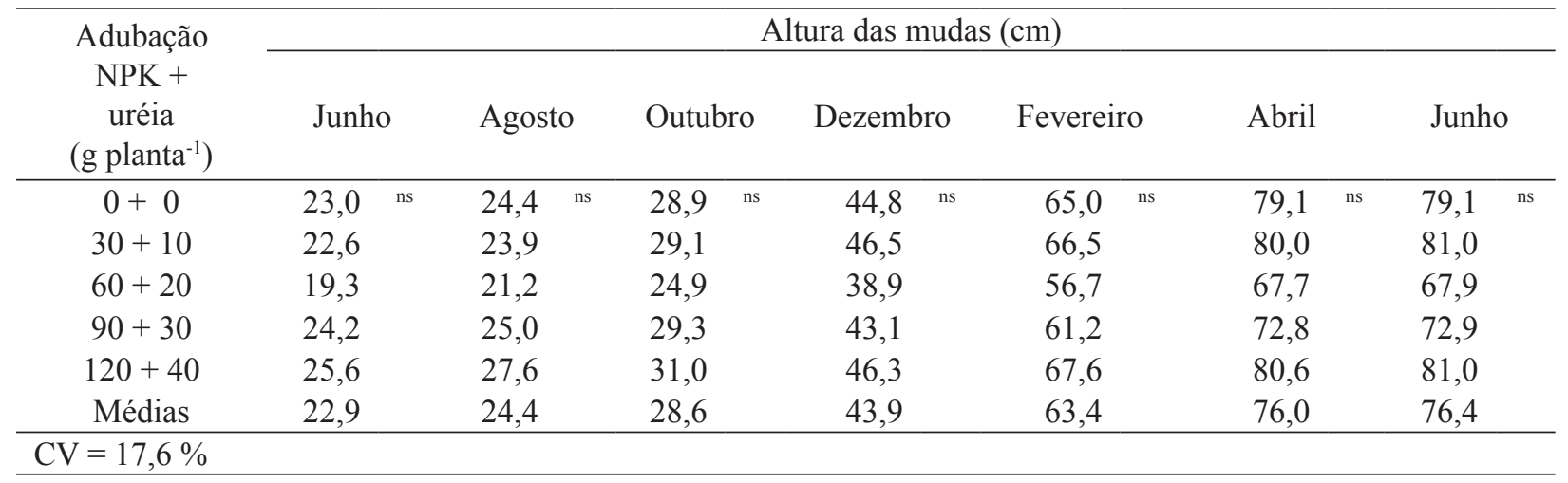

${ }^{\text {ns }}$ Diferenças não significativas nas colunas.

Tabela 4. Diâmetro $(\mathrm{cm})$ de Chamaecyparis lawsoniana a campo em função da adubação do solo em Pinhais, Paraná.

\begin{tabular}{|c|c|c|c|c|c|c|c|c|c|}
\hline \multirow{2}{*}{$\begin{array}{c}\text { Adubação } \\
\text { NPK + } \\
\text { uréia } \\
\left(\text { g planta }^{-1}\right)\end{array}$} & \multicolumn{9}{|c|}{ Diâmetro das mudas $(\mathrm{cm})$} \\
\hline & Junho & Agosto & Outubro & Dezembro & Fevereiro & Abril & & Junho & \\
\hline 0 & 0,32 ns & 0,38 & 0,48 & 0,77 & $1,21 \mathrm{~ns}$ & 1,54 & ns & 1,63 & ns \\
\hline $30+10$ & 0,29 & 0,33 & 0,43 & 0,74 & 1,17 & 1,49 & & 1,63 & \\
\hline $60+20$ & 0,27 & 0,31 & 0,39 & 0,60 & 1,07 & 1,33 & & 1,42 & \\
\hline $90+30$ & 0,33 & 0,37 & 0,47 & 0,74 & 1,12 & 1,34 & & 1,42 & \\
\hline $120+40$ & 0,37 & 0,44 & 0,49 & 0,76 & 1,22 & 1,57 & & 1,67 & \\
\hline Médias & 0,32 & 0,37 & 0,45 & 0,72 & 1,16 & 1,45 & & 1,55 & \\
\hline
\end{tabular}

${ }^{\text {ns }}$ Diferenças não significativas nas colunas.

A absorção de $40 \mathrm{~kg}$ de nitrogênio por hectare ao ano é requisitada para elevada produtividade primária líquida em florestas de coníferas (EPSTEIN; BLOOM, 2006). Neste estudo foram aplicados de 57 a $228 \mathrm{~kg}$ de nitrogênio por hectare o que não provocou alteração no crescimento das plantas. Em Pinus sylvestris também não houve alteração no diâmetro das mudas com a adubação em cobertura de 56 a $224 \mathrm{~kg}$ de nitrogênio por hectare (HENSLEY; ALDRIDGE, 1989). Uma vez atendida a necessidade nutricional da planta, seja pela fertilidade original do solo ou pelo fornecimento de nutrientes, a adubação adicional não resultou em maior crescimento das mudas. Altas aplicações de fertilizantes reduzem a eficiência de absorção de nutrientes pelas plantas, ou seja, a quantidade de nutriente absorvido por unidade de nutriente aplicado (EPSTEIN; BLOOM, 2006).

Respostas positivas de crescimento de coníferas em relação à adubação foram encontradas em estudos realizados com plantas cultivadas em vasos ou recipientes individuais, variando-se níveis de pH e macronutrientes (HENRY; BALAZICH; HINESLEY, 1992; THOMAS; RICHARDS; SPURWAY, 1995). Este fato pode ser uma evidência de que as mudas de coníferas possuem sistema de raízes hábil em se desenvolver e extrair nutrientes do solo, implicando na necessidade de espaço 
físico para seu desenvolvimento. Em condições de restrição ao crescimento de raízes, o fornecimento de nutrientes à planta torna-se fundamental para estas espécies.

$\mathrm{O}$ crescimento das mudas em diâmetro foi maior do que em altura em todo o período estudado. As mudas apresentaram crescimento mais lento de junho a outubro $(24,9 \%$ em altura e $40,6 \%$ em diâmetro) seguido de crescimento acentuado de outubro a abril (165,7\% em altura e 222,2\% em diâmetro), ao final do período de abril a junho, época de parada natural de crescimento pelas baixas temperaturas, $\mathrm{o}$ crescimento foi baixo $(0,5 \%$ em altura e $6,9 \%$ em

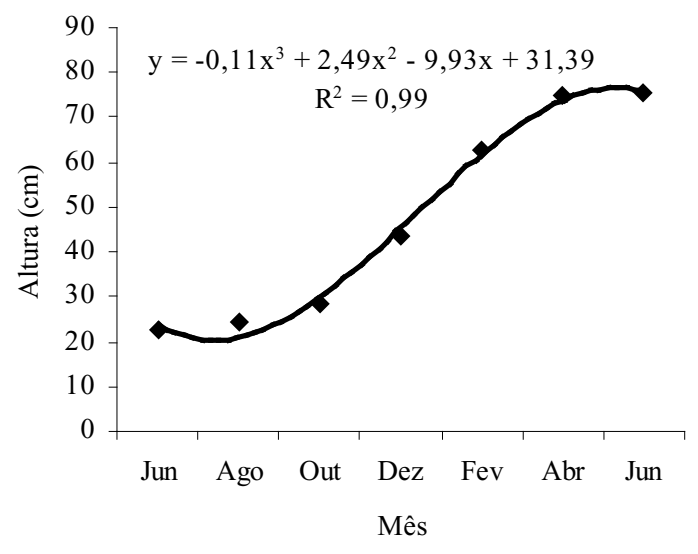

diâmetro). As dimensões médias finais das mudas foram altura de $76,4 \mathrm{~cm}$ e diâmetro de $1,55 \mathrm{~cm}$.

A análise do crescimento das mudas a campo em diâmetro e em altura (Figura 1) resultou em regressões cúbicas significativas com elevada correlação $(r=0,99)$. A interação entre os fatores adubação e época do ano não foi significativa (Prob. $>\mathrm{F}=0,99)$. O crescimento lento de junho a outubro é em função do clima regional mais frio, enquanto de outubro até abril o crescimento é mais acelerado devido à elevação da temperatura na primavera-verão. Após o mês de abril as baixas temperaturas voltam a ocorrer, reduzindo ou até mesmo paralisando o crescimento das plantas.

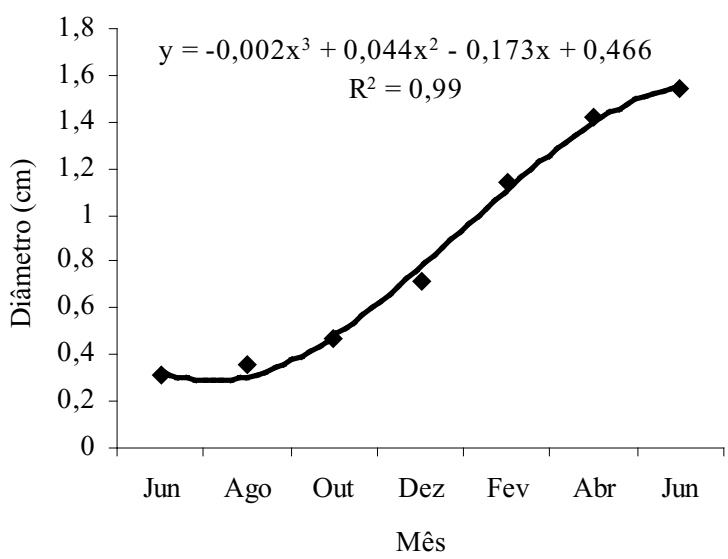

Figura 1. Crescimento em altura e diâmetro de Chamaecyparis lawsoniana durante 13 meses de cultivo a campo iniciado em maio em Pinhais, Paraná.

As adubações efetuadas no substrato foram eficientes na aceleração do crescimento das mudas mais significativamente a partir de janeiro. Os primeiros meses após o transplante se caracterizaram como um período de adaptação da muda ao novo substrato e de restabelecimento do sistema radicial podado por ocasião do transplante. O pequeno volume de substrato explorado pelas raízes da muda inicialmente fez com que os efeitos benéficos da adubação não tenham sido significativos nesta etapa. Apenas de quatro a seis meses após o transplante o efeito da adubação tornou-se significativo (Tabela 5 e 6). 
Tabela 5. Altura de mudas (cm) de Chamaecyparis lawsoniana em função da adubação do substrato para o crescimento em recipiente num período de um ano em Pinhais, Paraná.

\begin{tabular}{|c|c|c|c|c|c|c|c|c|c|c|c|c|c|c|}
\hline \multirow{3}{*}{$\begin{array}{c}\begin{array}{c}\text { Adubação } \\
\text { NPK }+ \\
\text { uréia } \\
\left(\text { g planta }^{-1}\right)\end{array} \\
0\end{array}$} & \multicolumn{14}{|c|}{ Altura das mudas $(\mathrm{cm})$} \\
\hline & \multicolumn{2}{|c|}{ Julho } & \multicolumn{2}{|c|}{ Setembro } & \multicolumn{2}{|c|}{ Novembro } & \multicolumn{2}{|c|}{ Janeiro } & \multicolumn{2}{|c|}{ Março } & \multicolumn{2}{|c|}{ Maio } & \multicolumn{2}{|c|}{ Julho } \\
\hline & 17,2 & $a^{*}$ & 19,7 & $\mathrm{a}$ & 29,2 & b & 37,9 & $\mathrm{c}$ & 46,8 & $\mathrm{c}$ & 50,8 & $\mathrm{c}$ & 50,8 & c \\
\hline $10+4$ & 18,1 & $\mathrm{a}$ & 20,2 & $\mathrm{a}$ & 30,3 & $a b$ & 42,5 & b & 52,5 & $\mathrm{~b}$ & 59,2 & $\mathrm{~b}$ & 59,2 & $b$ \\
\hline $20+8$ & 19,2 & $\mathrm{a}$ & 21,6 & $\mathrm{a}$ & 33,1 & $\mathrm{a}$ & 46,6 & a & 58,5 & $\mathrm{a}$ & 65,8 & a & 65,9 & $\mathrm{a}$ \\
\hline $30+12$ & 17,7 & $\mathrm{a}$ & 19,4 & $\mathrm{a}$ & 30,5 & $a b$ & 44,0 & $a b$ & 60,0 & $\mathrm{a}$ & 66,9 & $\mathrm{a}$ & 67,2 & $\mathrm{a}$ \\
\hline $40+16$ & 18,4 & $\mathrm{a}$ & 19,8 & $\mathrm{a}$ & 29,6 & $a b$ & 43,0 & $\mathrm{~b}$ & 60,0 & $\mathrm{a}$ & 68,0 & $\mathrm{a}$ & 68,1 & $\mathrm{a}$ \\
\hline
\end{tabular}

* Médias seguidas de mesma letra nas colunas não diferem significativamente pelo teste de Duncan ao nível de significância de $5 \%$.

Tabela 6. Diâmetro do tronco $(\mathrm{cm})$ a $3 \mathrm{~cm}$ do substrato de mudas de Chamaecyparis lawsoniana cultivada em recipiente em função da adubação do substrato para crescimento num período de um ano em Pinhais, Paraná.

\begin{tabular}{|c|c|c|c|c|c|c|c|c|c|c|c|c|c|c|}
\hline \multirow{2}{*}{$\begin{array}{c}\text { Adubação } \\
\text { NPK + } \\
\text { uréia } \\
\left(\mathrm{g} \mathrm{planta}^{-1}\right)\end{array}$} & \multicolumn{14}{|c|}{ Diâmetro das mudas $(\mathrm{cm})$} \\
\hline & \multicolumn{2}{|c|}{ Julho } & \multicolumn{2}{|c|}{ Setembro } & \multicolumn{2}{|c|}{ Novembro } & \multicolumn{2}{|c|}{ Janeiro } & \multicolumn{2}{|c|}{ Março } & \multicolumn{2}{|c|}{ Maio } & \multicolumn{2}{|c|}{ Julho } \\
\hline 0 & 0,22 & $a^{*}$ & 0,29 & $\mathrm{a}$ & 0,36 & $\mathrm{~b}$ & 0,48 & $\mathrm{c}$ & 0,53 & $\mathrm{~d}$ & 0,60 & $\mathrm{~d}$ & 0,61 & $\mathrm{~d}$ \\
\hline $10+4$ & 0,24 & $\mathrm{a}$ & 0,31 & $\mathrm{a}$ & 0,35 & $\mathrm{~b}$ & 0,52 & $\mathrm{bc}$ & 0,60 & $\mathrm{c}$ & 0,71 & c & 0,72 & $\mathrm{c}$ \\
\hline $20+8$ & 0,27 & $\mathrm{a}$ & 0,31 & $\mathrm{a}$ & 0,42 & $\mathrm{a}$ & 0,61 & $\mathrm{a}$ & 0,70 & $\mathrm{~b}$ & 0,83 & $\mathrm{~b}$ & 0,84 & $\mathrm{~b}$ \\
\hline $30+12$ & 0,22 & $\mathrm{a}$ & 0,30 & $\mathrm{a}$ & 0,36 & $\mathrm{~b}$ & 0,56 & $\mathrm{ab}$ & 0,70 & $\mathrm{~b}$ & 0,82 & $\mathrm{~b}$ & 0,84 & $\mathrm{~b}$ \\
\hline $40+16$ & 0,28 & $\mathrm{a}$ & 0,30 & $\mathrm{a}$ & 0,37 & $a b$ & 0,59 & $\mathrm{a}$ & 0,77 & $\mathrm{a}$ & 0,90 & $\mathrm{a}$ & 0,90 & $\mathrm{a}$ \\
\hline $\mathrm{CV}=7,8 \%$ & & & & & & & & & & & & & & \\
\hline
\end{tabular}

* Médias seguidas de mesma letra nas colunas não diferem significativamente pelo teste de Duncan ao nível de significância de 5\%.

Considerando-se um ciclo de um ano de crescimento, as mudas que receberam os três níveis mais elevados de adubação apresentaram valores superiores às demais em altura e diâmetro do tronco. Esta resposta das plantas em relação ao seu porte justifica a adubação do substrato, uma vez que os viveiristas preconizam o crescimento mais acelerado das mudas para atingir um padrão de mercado mais rapidamente.

A adubação do substrato não alterou o período de crescimento das plantas, pois mesmo as mudas mais adubadas apresentaram crescimento significativo somente no período de setembro a maio. Com a chegada das baixas temperaturas de inverno o crescimento das mudas em altura e diâmetro retardou ou mesmo paralisou em alguns casos.
As mudas que receberam maior adubação apresentaram altura final de $68,1 \mathrm{~cm}$ e diâmetro do tronco de 0,90 cm contra 50,8 cm de altura e $0,61 \mathrm{~cm}$ de diâmetro do tronco da testemunha. As maiores alterações de crescimento ocorreram no aumento do diâmetro do tronco da muda, demonstrando maior resposta de crescimento secundário em relação à adubação. As mudas mais bem adubadas apresentaram um acréscimo de 47,5 \% em diâmetro em relação às testemunhas, enquanto o acréscimo em altura foi de 34,1\%. A análise desses valores resultou em regressões cúbicas significativas para a altura e diâmetro das plantas (Figuras 2 e 3). Houve elevada correlação $(r=0,99)$ entre o crescimento em altura e diâmetro pelas mudas. 


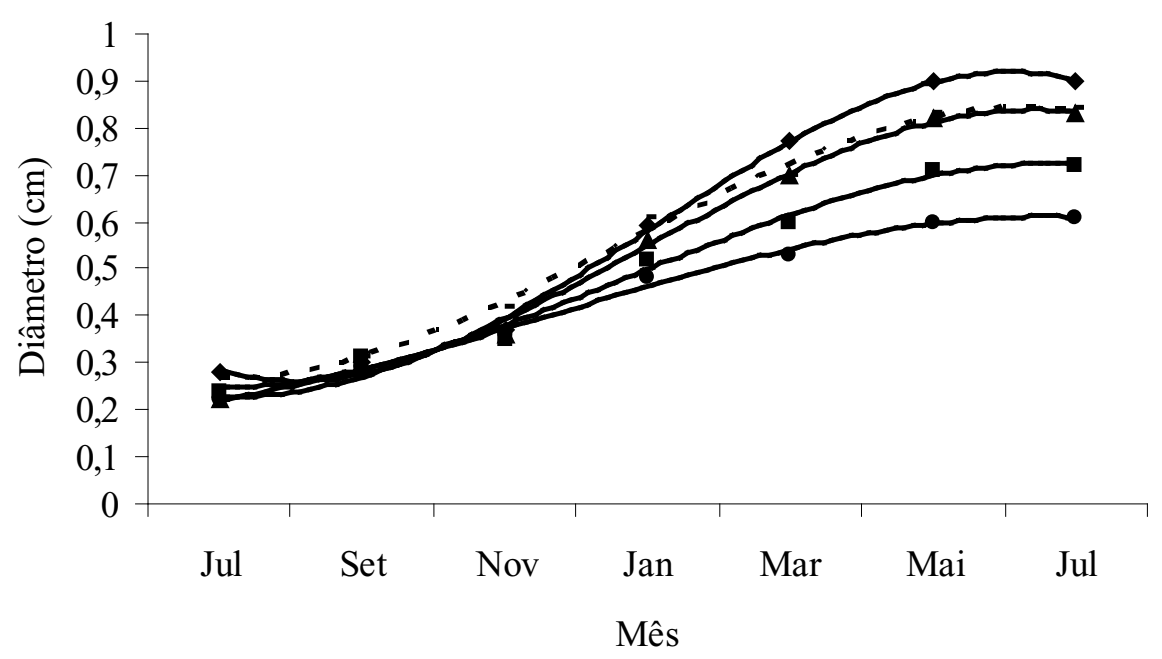

$\bullet \mathrm{T} 0$ - $\mathrm{T} 1-\mathrm{T} 2 \Delta \mathrm{T} 3 \bullet \mathrm{T} 4$

Figura 2. Crescimento em altura de Chamaecyparis lawsoniana durante 12 meses de cultivo em recipiente iniciado em julho em Pinhais, Paraná. Tratamentos representam doses de NPK (4-30-10) + uréia em g planta ${ }^{-1} \cdot\left(\mathrm{y}_{\text {т }(0+0)}=\right.$ $-0,0524 \mathrm{x}^{3}+0,8246 \mathrm{x}^{2}+0,464 \mathrm{x}+16,81 ; \mathrm{R}^{2}=0,99 ; \mathrm{y}_{\mathrm{T} 1(30+10)}=-0,0697 \mathrm{x}^{3}+1,1597 \mathrm{x}^{2}-0,448 \mathrm{x}+17,8 ; \mathrm{R}^{2}=0,99 ; \mathrm{y}_{\mathrm{T} 2(60+20)}=$ $-0,08 \mathrm{x}^{3}+1,3353 \mathrm{x}^{2}-0,6014 \mathrm{x}+18,89 ; \mathrm{R}^{2}=0,99 ; \mathrm{y}_{\mathrm{T} 3(90+30)}=-0,0956 \mathrm{x}^{3}+1,6511 \mathrm{x}^{2}-1,9432 \mathrm{x}+17,63 ; \mathrm{R}^{2}=0,99 ; \mathrm{y}_{\mathrm{T} 4}$ $\left.{ }_{(120+40)}=-0,1004 \mathrm{x}^{3}+1,7837 \mathrm{x}^{2}-2,8160 \mathrm{x}+18,59 ; \mathrm{R}^{2}=0,99\right)$

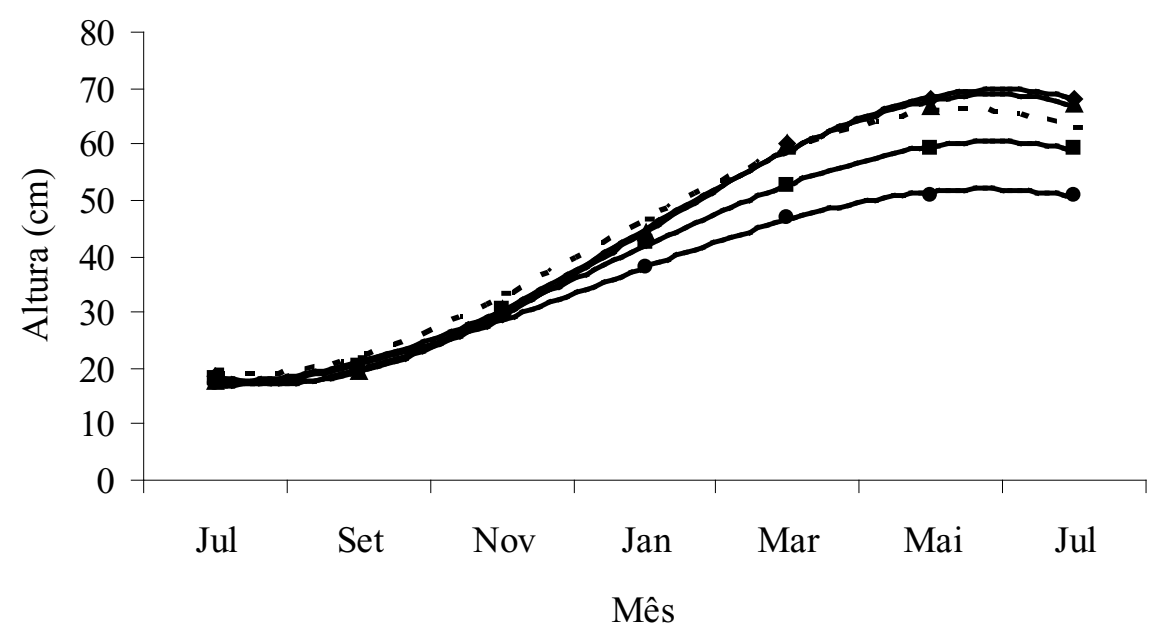

- $\mathrm{T} 0$ - $\mathrm{T} 1-\mathrm{T} 2 \boldsymbol{\Delta} \mathrm{T} 3 \bullet \mathrm{T} 4$

Figura 3. Crescimento do caule em diâmetro de Chamaecyparis lawsoniana durante 12 meses de cultivo em recipiente iniciado em julho em Pinhais, Paraná. Tratamentos representam doses de NPK (4-30-10) + uréia em g planta ${ }^{-1}$. $\left(\mathrm{y}_{\text {T0 }}\right.$ ${ }_{(0+0)}=-0,0003 \mathrm{x}^{3}+0,0043 \mathrm{x}^{2}+0,026 \mathrm{x}+0,22 ; \mathrm{R}^{2}=0,99 ; \mathrm{y}_{\mathrm{T} 1(30+10)}=-0,0006 \mathrm{x}^{3}+0,0104 \mathrm{x}^{2}+0,0006 \mathrm{x}+0,25 ; \mathrm{R}^{2}=0,99 ; \mathrm{y}_{\mathrm{T} 2}$ ${ }_{(60+20)}=-0,0008 \mathrm{x}^{3}+0,0133 \mathrm{x}^{2}+0,0006 \mathrm{x}+0,27 ; \mathrm{R}^{2}=0,99 ; \mathrm{y}_{\mathrm{T}(90+30)}=-0,0009 \mathrm{x}^{3}+0,0156 \mathrm{x}^{2}-0,0085 \mathrm{x}+0,23 ; \mathrm{R}^{2}=0,99 ;$ $\left.\mathrm{y}_{\mathrm{T} 4(120+40)}=-0,0013 \mathrm{x}^{3}+0,0239 \mathrm{x}^{2}-0,0465 \mathrm{x}+0,28 ; \mathrm{R}^{2}=0,99\right)$ 
Em outros estudos com coníferas, mudas de Chamaecyparis lawsoniana desenvolveram-se bem em substratos com $\mathrm{pH}$ 4,5 com pouco ou nenhum calcário (THOMAS; RICHARDS; SPURWAY, 1995). A altura de mudas sofreu alterações em virtude da adubação nitrogenada (HENRY; BALAZICH; HINESLEY, 1992), já o comprimento de raízes de Cryptomeria japonica decresceu com o aumento das adubações nitrogenadas (JULL; WARREN; BLAZICH, 1994). A adubação com 80 a 90 g de nitrogênio e $40 \mathrm{~g}$ de fósforo por metro cúbico de substrato promoveu maior taxa de crescimento de mudas de Chamaecyparis lawsoniana (THOMAS; RICHARDS; SPURWAY, 1995).

Na produção de mudas em recipientes individuais a adubação contribui para que o porte exigido para transplante seja atingido mais rapidamente, pois o crescimento inicial do caule tanto em altura quanto em diâmetro é acelerado. Assim, benefícios podem ser alcançados, por exemplo, num programa de reflorestamento para seqüestro de carbono, pela economia de tempo e investimento para a formação das mudas. A adubação do substrato em recipientes foi favorável para a produção de mudas, porém a campo, embora as mudas não tenham respondido à adubação, o crescimento da planta foi maior. A qualidade da muda é fundamental para o início do cultivo destas espécies no local definitivo e para assegurar também o seu valor ornamental.

\section{Conclusões}

A adubação em cobertura em mudas a campo em viveiro não interferiu no crescimento de mudas de Chamaecyparis lawsoniana.

A adubação de substrato promoveu maior crescimento demudas de Chamaecyparis lawsoniana em recipientes em altura e em diâmetro de tronco. $\mathrm{O}$ crescimento das mudas foi significativo somente no período de setembro a maio, mesmo nas adubações com níveis mais elevados de nutrientes.
O crescimento em diâmetro do tronco da muda foi mais influenciado, demonstrando que o crescimento secundário da planta foi mais estimulado pela adubação.

O crescimento das mudas a campo foi maior que o ocorrido em recipientes.

\section{Referências}

BRILES, C. E.; WHITLOCK, C.; BARTLEIN, P. J.; HIGUERA, P. Regional and local controls on postglacial vegetation and fire in the Siskiyou Mountains, northern California, USA. Palaeogeography, Palaeoclimatology, Palaeoecology, Amsterdan, v. 265, p. 159-169, 2008.

CRAIG, A. M.; KARCHESY, J. J.; BLYTHE, L. L.; GONZÁLEZ-HAERNÁNDEZ, M. P.; SWAN, L. R. Toxicity studies on western juniper oil (Juniperus occidentalis) and Port-Orford-cedar oil (Chamaecyparis lawsoniana) extracts utilizing local lymph node and acute dermal irritation assays. Toxicology Letters, Amsterdam, v. 154, n. 3, p. 217-224, 2004.

EPSTEIN, E.; BLOOM, A. J. Nutrição mineral de plantas: princípios e perspectivas. Londrina: Planta, 2006.

HENRY, P. H.; BALAZICH, F. A.; HINESLEY, L. E. Nitrogen nutrition of containerized eastern redcelar. I. Growth, mineral nutrient concentrations and carbohydrate status. Journal of the American Society for Horticultural Science, Alexandria, v. 117, n. 4, p. 563-567, 1992.

HENSLEY, D. L.; ALBRIDGE, E. G. Postplant application of nitrogen fertilizers to Pinus sylvestris at different stages of stablishment. Journal of Environmental Horticulture, Washington, v. 7, n. 3, p. 112-114, 1989.

JULL, L. G.; WARREN, S. L.; BLAZICH, F. A. Nitrogen nutrition of containerized Cryptomeria japonica Elegans aurea. Journal of Environmental Horticulture, Washington, v. 12, n. 4, p. 212-215, 1994.

LORENZI, H.; SOUZA, H. M. Plantas ornamentais no Brasil: arbustivas, herbáceas e trepadeiras. Nova Odessa: Plantarum, 1995.

RAIJ, V. B. Fertilidade do solo e adubação. Piracicaba: Ceres, Potafós, 1991.

SMITH, E. C. J.; WILLIAMSON, E. M.; WAREHAM, N.; KAATZ, G. W.; GIBBONS, S. Antibacterials and modulators of bacterial resistance from the immature cones of Chamaecyparis lawsoniana. Phytochemistry, New York, v. 68, p. 210-217, 2007. 
SOARES, C. P. B.; OLIVEIRA, M. L. R. Equações para estimar a quantidade de carbono na parte aérea de árvores de eucalipto em Viçosa, Minas Gerais. Revista Árvore, Viçosa, v. 26, n. 5, p. 533-539, 2002.

STUMPF, E. R. T.; GROLLI, P. R.; SILVA, J. A. G. Enraizamento de estacas de Chamaecyparis lawsoniana Parl. em cinco substratos com uso de ácido indolbutírico. Ciência Rural, Santa Maria, v. 29, n. 2, p. 207-211, 1999.

STUMPF, E. R. T.; GROLLI, P. R.; SCZEPANSKI, P. H. G. Efeito do ácido indolbutírico, substrato e tipo de estaca no enraizamento de Chamaecyparis lawsoniana
Parl. Revista Brasileira de Agrociência, Pelotas, v. 7, n. 2, p. 101-105, 2001.

THOMAS, M. B.; RICHARDS, D. A. J.; SPURWAY, M. I. Influence of nutrition on foliage growth and tip necroses on container-grown Chamaecyparis lawsoniana 'Ellwood's Gold'. In: COMBINED PROCEEDINGS OF THE INTERNATIONAL PLANT PROPAGATORS' SOCIETY, 23., 1995, Washington. Proceedings... Washington: International Plant Propagators' Society, 1995. p. 396-403.

TOMÉ JUNIOR, J. B. Manual para interpretação de análise de solo. Guaíba: Agropecuária, 1997. 